\title{
Determinação da metodologia para o teste de germinação de sementes de Eucalyptus urophylla S. T. Blake (Myrtaceae)
}

\author{
Tatiane Sanches Jeromini ${ }^{1 *}$ \\ Thais Arroyo da Cruz ${ }^{2}$ \\ Thaís Soares Pereira ${ }^{1}$ \\ Givanildo Zildo da Silva ${ }^{3}$ \\ Cibele Chalita Martins ${ }^{1}$ \\ ${ }^{1}$ Universidade Estadual Paulista “Júlio de Mesquita Filho" \\ Faculdade de Ciências Agrárias e Veterinárias, Campus de Jaboticabal \\ Via de Acesso Professor Paulo Donato Castelane Castellane s/n \\ CEP 14.884-900, Jaboticabal - SP, Brasil \\ ${ }^{2}$ Ourofino Agrociência, Ribeirão Preto - SP, Brasil \\ ${ }^{3}$ Universidade Federal de Goiás, Regional de Jataí, Jataí - GO, Brasil \\ * Autor para correspondência \\ tatiane_jeromini@hotmail.com
}

Submetido em 26/11/2019

Aceito para publicação em 26/03/2020

\section{Resumo}

Eucalyptus urophylla S. T. Blake é uma das principais espécies de eucaliptos cultivadas. Entretanto, não existem recomendações para o teste padrão de germinação de $E$. urophylla. Assim, o objetivo foi determinar a melhor metodologia para a condução do teste de germinação de sementes de E. urophylla. O experimento foi dividido em duas etapas. Na primeira, foram testados dois substratos (sobre papel mata-borrão e areia) e seis temperaturas (constantes de $15,20,25,30,35^{\circ} \mathrm{C}$ e alternada de $20-30^{\circ} \mathrm{C}$, entre noite e dia, respectivamente) na condução do teste de germinação. Na segunda etapa, foi selecionado o substrato mais indicado no experimento anterior e testado em dois lotes, nas seis temperaturas citadas anteriormente. Foram avaliadas a germinação, primeira contagem, índice de velocidade e tempo médio de germinação. $\mathrm{O}$ experimento foi realizado em delineamento inteiramente casualizado com quatro repetições e os tratamentos foram dispostos em esquema fatorial de 2 × 6 para ambas as etapas. Na comparação da germinação entre os lotes, observou-se que o lote 1 apresentou menor desempenho do que o lote 2 nas condições de temperaturas extremas. $\mathrm{O}$ teste de germinação de sementes de E. urophylla deve ser realizado a 30 ou $35^{\circ} \mathrm{C}$ com semeadura sobre papel ou areia, e com contagem inicial e final aos quatro e 10 dias após a semeadura, respectivamente. Com base nesta pesquisa, mais testes podem ser realizados, para outros lotes e sementes de E. urophylla de outras procedências, para garantir a confirmação dos resultados.

Palavras-chave: Duração do teste; Espécie florestal; Qualidade fisiológica; Padronização; Viabilidade

\section{Abstract}

Determining the methodology for testing seed germination of Eucalyptus urophylla S. T. Blake (Myrtaceae). Eucalyptus urophylla S. T. Blake is one of the main eucalyptus species cultivated. However, there 
are no recommendations for testing its germination pattern. Thus, the objective of this work was to determine the best methodology to conduct seed germination tests for E. urophylla. The study was divided into two steps. In the first, two substrates (on paper and sand) and six temperatures $\left(15,20,25,30,35^{\circ} \mathrm{C}\right.$, and alternating $20-30^{\circ} \mathrm{C}$, between night and day, respectively) were tested. In the second step, the best substrate was selected based on the first experiment and was tested in two seeds lots and at the six temperatures previously mentioned. Germination, first count, speed index and the average germination time were evaluated. The experiment was in a completely randomized design with four replications and the treatments were arranged in a $2 \times 6$ factorial scheme for both steps. When comparing germination between lots, it was observed that lot 1 had a lower performance than lot 2 under extreme temperature conditions. Seed germination tests of E. urophylla should be made at 30 or $35^{\circ} \mathrm{C}$ on the paper or sand substrate, with the initial and final counts at four and 10 days after sowing, respectively. Based on this study, more tests should be made with seeds from other lots and populations of E. urophylla to confirm the results.

Key words: Forest species; Physiological quality; Standardization; Test Time; Viability

\section{Introdução}

O Brasil é um dos países mais desenvolvidos no setor florestal, com alta produtividade e menor custo de produção em relação a outros países do mundo. Esse quadro é devido aos avanços tecnológicos como introdução de material genético melhorado, mecanização das atividades florestais e condições edafoclimáticas favoráveis à produção de madeira e seus derivados (SANTOS et al., 2017).

No Brasil o gênero Eucalyptus ocupa a maior área de exploração e possui a maior produção de madeira em relação às outras espécies (IBGE, 2018). O Eucalyptus urophylla S.T. Blake se destaca como uma das espécies mais plantadas na região Sudeste do país, para a produção de lenha, carvão, madeira e celulose (LOPES et al., 2014). Essa espécie apresenta adaptabilidade a diversas condições edafoclimáticas, rusticidade, resistência ao déficit hídrico, alto potencial de crescimento, produtividade, além de comprovada resistência ao cancro-do-eucalipto (Cryphonectria cubensis Bruner). Devido a essas características $E$. urophylla é amplamente utilizado para produção de híbridos (WILCKEN et al., 2008; SOUZA et al., 2011).

Além da sua importância dentro de programas de melhoramento, para estudos de adaptação e caracterização de plantas, a propagação por sementes é viável e utilizada comercialmente, principalmente por pequenos viveiros de mudas e também para produção de jardins clonais (MARTINS et al., 2014). Dentro do processo de produção e comercialização de sementes, é necessária a padronização e consolidação das normas das análises de qualidade das sementes em laboratório, principalmente para determinar a taxa de semeadura, a comparação de lotes de sementes e para estabelecer padrões de comercialização (MARTINS et al., 2008; CETNARSKI FILHO; CARVALHO, 2009).

O teste de germinação é o mais utilizado para determinar a qualidade fisiológica das sementes, sendo realizado em laboratório sob condições controladas de temperatura, substrato e luz, possibilitando que as sementes expressem o máximo poder germinativo sem que haja interferências externas indesejáveis (SANTANA et al., 2010).

Nas Regras de Análise de Sementes (RAS) encontrase a descrição de normas para o teste de germinação para 47 espécies do gênero Eucalyptus (BRASIL, 2009; 2013). As temperaturas recomendadas variam de 15 a $35^{\circ} \mathrm{C}$, em regime constante, ou a alternada de $20-30^{\circ} \mathrm{C}$, entre noite e dia, respectivamente, demonstrando que esse fator depende da espécie. Em relação aos substratos verificou-se para todas essas espécies a recomendação da semeadura sobre papel ou entre areia (BRASIL, 2013). Vale salientar que, nas Instruções para Análise de Sementes de Espécies Florestais, não existe um trabalho científico para o estabelecimento da metodologia para a espécie em estudo.

As normas e procedimentos para a condução e avaliação do teste de germinação das espécies são periodicamente revistos por um comitê formado por pesquisadores e profissionais da área. Porém, as atualizações e inserções de procedimentos somente 
podem ser realizadas com base em resultados de pesquisa, e esses procedimentos devem possibilitar que a germinação ocorra nas condições ótimas de cada espécie (BRASIL, 2009; TOMAZ et al., 2016). Deste modo, objetivou-se com esta pesquisa determinar a melhor metodologia para a condução do teste de germinação de sementes de E. urophylla.

\section{Material e Métodos}

As sementes de E. urophylla foram coletadas em Anhembi-SP em Área de Produção de Sementes (APS-F1) do Instituto de Pesquisas e Estudos Florestais (IPEF) e encaminhadas para o Laboratório de Análise de Sementes do Departamento de Produção Vegetal da Faculdade de Ciências Agrárias e Veterinárias da UNESP, Campus de Jaboticabal - SP. O lote 1, da cultivar LCFA012, foi colhido no talhão A10B71 e o lote 2 da cultivar LCFA006 no talhão A8C50.

As sementes foram classificadas por tamanho em peneiras de malha metálica e separadas para serem utilizadas aquelas sementes retidas nas peneiras com crivo de 0,71 a 1,00 mm de diâmetro. Essa classificação foi realizada para padronizar o tamanho das sementes a serem avaliadas dos dois lotes e aumentar a pureza física facilitando a separação manual das sementes puras.

\section{Experimento 1}

No primeiro experimento foram avaliados os efeitos das temperaturas e dos substratos sobre o processo germinativo das sementes, somente para o lote 2 .

A germinação foi conduzida com quatro subamostras de 100 sementes de E. urophylla, distribuídas uniformemente sobre duas folhas de papel mata-borrão e sobre areia, umedecidas com água destilada na quantidade de 2,5 vezes sua massa seca para o papel e $60 \%$ de capacidade de retenção para a areia, respectivamente (BRASIL, 2009), e acondicionadas em caixas de plástico transparente $(11,0 \times 11,0 \mathrm{x}$ $3,5 \mathrm{~cm}$ ) com tampa. Os testes foram conduzidos sob seis temperaturas: cinco constantes $(15,20,25,30$, $\left.35^{\circ} \mathrm{C}\right)$ e uma alternada $\left(20-30^{\circ} \mathrm{C}\right.$, entre noite e dia, respectivamente), com fotoperíodo de $8 \mathrm{~h}$.
Foram realizadas contagens diárias do número de plântulas normais até a data de estabilização da germinação, verificada quando o número de plântulas normais se manteve estável por três dias de contagem sucessiva (AFFONSO et al., 2018; TOMAZ et al., 2015; 2016). Considerou-se plântula normal aquela que possuía parte aérea, raízes primárias íntegras e bem desenvolvidas e comprimento total de plântulas maior que $3 \mathrm{~mm}$; os resultados foram expressos em porcentagem (BRASIL, 2009; AFFONSO et al., 2018).

A primeira contagem de germinação foi determinada quando a germinação atingiu aproximadamente 50\% daquela obtida ao final do teste (AFFONSO et al., 2018; TOMAZ et al., 2015; 2016).

Índice de velocidade de germinação: realizado em conjunto com o teste de germinação e calculado com base na contagem diária das plântulas normais até a data final do teste de germinação de 26 dias e aplicando-se fórmula estabelecida por Maguire (1962).

Tempo médio de germinação: realizado em conjunto com o teste de geminação e calculado com base na fórmula estabelecida por Labouriau (1983).

\section{Experimento 2}

Após definido o substrato mais indicado (sobre papel) para a germinação, pela sua praticidade, foi instalado o segundo experimento com os dois lotes de sementes.

Para o teste de germinação, os lotes foram colocados para germinar em cinco temperaturas constantes $(15,20$, $\left.25,30,35^{\circ} \mathrm{C}\right)$ e uma alternada $\left(20-30^{\circ} \mathrm{C}\right)$ como citado anteriormente, com fotoperíodo de $8 \mathrm{~h}$. As sementes foram avaliadas quanto à germinação, primeira contagem, índice de velocidade de germinação e tempo médio de germinação, como descrito anteriormente.

Após a finalização do segundo experimento, foram identificadas duas temperaturas ideais, associadas ao substrato, para ambos os lotes para elaborar as curvas de germinação, visando à data da primeira contagem $(50 \%$ daquela obtida ao final do teste) e da contagem final do teste de germinação, utilizando os dois lotes (TOMAZ et al., 2015; 2016; AFFONSO et al., 2018). 


\section{Análise estatística}

A análise estatística para ambos os experimentos foi realizada em delineamento inteiramente casualizado com quatro repetições, e os tratamentos foram dispostos em esquema fatorial $2 \times 6$, sendo dois substratos e seis temperaturas no primeiro experimento e dois lotes e seis regimes de temperatura no segundo. Os dados foram submetidos ao teste de normalidade dos resíduos, avaliados pelo teste de Shapiro-Wilk e homocedastidade de Barlett. Foi realizada a análise de variância pelo teste $\mathrm{F}$ e as médias das características avaliadas foram comparadas pelo teste de Tukey, a 5\% de probabilidade com auxílio do software Sisvar. A figura foi criada com o auxílio do programa Excel.

\section{Resultados}

Constatou-se no primeiro experimento que não houve interação significativa entre os fatores substrato e temperatura para todas as variáveis avaliadas no processo germinativo das sementes de E. urophylla (Tabela 1).
Verificou-se somente efeito isolado da temperatura sobre a germinação, primeira contagem e índice de velocidade de germinação.

A germinação de sementes de E. urophylla ocorreu em ampla faixa de temperatura, embora as máximas porcentagens de germinação tenham sido verificadas quando o teste foi conduzido a 20,25 e $20-30^{\circ} \mathrm{C}$, sendo 91,95 e $92 \%$, respectivamente (Tabela 2). A porcentagem de germinação que ocorreu a $15^{\circ} \mathrm{C}$ não diferiu daquelas obtidas a 30 e $35^{\circ} \mathrm{C}$, onde se observaram médias de 89 e $87 \%$, respectivamente.

Em relação ao vigor, avaliado pelos testes de primeira contagem e índice de velocidade de germinação, verificou-se maior velocidade de germinação quando as sementes foram colocadas para germinar a 25,30 e $35^{\circ} \mathrm{C}$, enquanto as menores temperaturas, de 15 e $20^{\circ} \mathrm{C}$, foram prejudiciais para aumentar a velocidade do processo germinativo, 0 e $27 \%$ na primeira contagem e 6,09 e 13,50 para o índice de velocidade de germinação de sementes de E. urophylla, respectivamente.

TABELA 1: Resumo da análise de variância em sementes de E. urophylla submetidas a diferentes substratos e temperaturas.

\begin{tabular}{lcccc}
\hline \multirow{2}{*}{$\begin{array}{c}\text { Fonte de } \\
\text { variação }\end{array}$} & $\begin{array}{c}\text { Grau de } \\
\text { liberdade }\end{array}$ & $\begin{array}{c}\text { Germinação } \\
(\%)\end{array}$ & $\begin{array}{c}\text { Primeira contagem } \\
(\%)\end{array}$ & $\begin{array}{c}\text { Índice de velocidade de } \\
\text { germinação }\end{array}$ \\
\hline Substrato (S) & 1 & $0,02^{\text {ns }}$ & $18,75^{\text {ns }}$ & $1,69^{\text {ns }}$ \\
Temperatura (T) & 5 & $222,94^{* *}$ & $8522,93^{* *}$ & $414,12^{* *}$ \\
S x T & 5 & $36,87^{\text {ns }}$ & $154,75^{\text {ns }}$ & $4,35^{\text {ns }}$ \\
Resíduo & 36 & 34,84 & 66,18 & 4,01 \\
\hline CV $(\%)$ & & 6,64 & 15,22 & 10,87 \\
\hline
\end{tabular}

** significativo a $1 \%$ de probabilidade; ns - não significativo; CV - Coeficiente de variação.

TABELA 2: Germinação, primeira contagem e índice de velocidade de germinação de sementes de E. urophylla semeadas sobre papel e mantidas em diferentes temperaturas.

\begin{tabular}{cccc}
\hline $\begin{array}{c}\text { Temperatura } \\
\left({ }^{\circ} \mathbf{C}\right)\end{array}$ & $\begin{array}{c}\text { Germinação } \\
(\mathbf{\%})\end{array}$ & $\begin{array}{c}\text { Primeira contagem de } \\
\text { germinação (\%) }\end{array}$ & $\begin{array}{c}\text { Índice de velocidade de } \\
\text { germinação }\end{array}$ \\
\hline 15 & $80 \mathrm{~b}$ & $0 \mathrm{~d}$ & $6,09 \mathrm{~d}$ \\
20 & $91 \mathrm{a}$ & $27 \mathrm{c}$ & $13,50 \mathrm{c}$ \\
25 & $95 \mathrm{a}$ & $71 \mathrm{ab}$ & $22,18 \mathrm{ab}$ \\
30 & $89 \mathrm{ab}$ & $81 \mathrm{a}$ & $24,68 \mathrm{a}$ \\
35 & $87 \mathrm{ab}$ & $79 \mathrm{a}$ & $23,30 \mathrm{ab}$ \\
$20-30$ & $92 \mathrm{a}$ & $63 \mathrm{~b}$ & $20,73 \mathrm{~b}$ \\
\hline
\end{tabular}

Médias seguidas da mesma letra minúscula na coluna não diferem entre si pelo teste de Tukey ao nível de 5\% de probabilidade. 
No segundo experimento, constatou-se a interação significativa entre os fatores lote e temperatura para todas as variáveis avaliadas durante o processo germinativo das sementes de E. urophylla, exceto para o índice de velocidade de germinação, para o qual se verificou somente efeito isolado desses fatores (Tabela 3).

Ao comparar isoladamente o índice de velocidade de germinação entre os lotes 1 e 2 , foi possível verificar maior vigor no segundo, pois apresentou um índice de 25,175 , enquanto o lote 1 apresentou índice de 18,59 (Tabela 3).

Para os dois lotes, todas as condições de temperatura possibilitaram a obtenção da máxima porcentagem de germinação, exceto $15^{\circ} \mathrm{C}$ para o lote 1 (Tabela 4). Na comparação da germinação entre os lotes, observou-se que o lote 1 apresentou menor desempenho do que o lote 2 nas condições de temperaturas extremas: mínimas de 15 e $20^{\circ} \mathrm{C}$ e máxima de $35^{\circ} \mathrm{C}$ com médias de 76,91 e $88 \%$, respectivamente.
Por meio dos testes de vigor, também foram verificados indícios de menor qualidade do lote $1 \mathrm{em}$ comparação ao 2. Esse comportamento foi observado em quase todas as temperaturas avaliadas. No teste de primeira contagem de germinação somente a temperatura de $30^{\circ} \mathrm{C}$ possibilitou valores similares e máximos para os dois lotes. Na temperatura de $15^{\circ} \mathrm{C}$ os valores foram idênticos, porém nulos. Para o tempo médio de germinação, verificou-se velocidade igual no teste conduzido a temperatura constante de $25^{\circ} \mathrm{C}$ e alternada de $20-30^{\circ} \mathrm{C}$. No entanto, essas condições de temperatura para o teste não possibilitaram o menor tempo médio de germinação para ambos os lotes.

Para o tempo médio de germinação, o lote 1 apresentou médias similares nas temperaturas de 25, 30, 35 e $20-30^{\circ} \mathrm{C}$, necessitando de quatro a cinco dias para concluir o processo germinativo, enquanto, no lote 2 , as sementes colocadas para germinar nas temperaturas de 30 e $35^{\circ} \mathrm{C}$ reduziram o tempo para concluir a

TABELA 3: Resumo da análise de variância em sementes de dois lotes de E. urophylla submetidos à diferentes temperaturas semeadas sobre papel.

\begin{tabular}{lccccc}
\hline \multirow{2}{*}{$\begin{array}{c}\text { Fonte de } \\
\text { variação }\end{array}$} & $\begin{array}{c}\text { Grau de } \\
\text { liberdade }\end{array}$ & $\begin{array}{c}\text { Germinação } \\
(\%)\end{array}$ & $\begin{array}{c}\text { Primeira contagem } \\
\text { de germinação (\%) }\end{array}$ & $\begin{array}{c}\text { Índice de velocidade } \\
\text { de germinação }\end{array}$ & $\begin{array}{c}\text { Tempo médio de } \\
\text { germinação (dias) }\end{array}$ \\
\hline Lotes (L) & 1 & $808,52^{* *}$ & $6417,19^{* *}$ & $519,03^{* *}$ & $50,02^{* *}$ \\
Temperatura (T) & 5 & $122,04^{* *}$ & $9363,92^{* *}$ & $466,62^{* *}$ & $93,62^{* *}$ \\
L x T & 5 & $56,36^{*}$ & $781,49^{* *}$ & $5,22^{\text {ns }}$ & $8,32^{* *}$ \\
Resíduo & 36 & 16,12 & 62,98 & 2,89 & 0,58 \\
\hline CV (\%) & & 4,32 & 12,10 & 7,77 & 12,88 \\
\hline
\end{tabular}

** significativo a $1 \%$ de probabilidade; ${ }^{*}$ significativo a $5 \%$ de probabilidade; ${ }^{\text {ns }}$ - não significativo; CV - Coeficiente de variação.

TABELA 4: Germinação, primeira contagem e tempo médio de germinação de dois lotes de sementes de E. urophylla semeadas sobre papel e mantidas em diferentes temperaturas.

\begin{tabular}{|c|c|c|c|c|c|c|c|}
\hline \multirow[t]{2}{*}{$\begin{array}{c}\text { Temperatura } \\
\left({ }^{\circ} \mathrm{C}\right)\end{array}$} & \multicolumn{2}{|c|}{$\begin{array}{c}\text { Germinação } \\
(\%)\end{array}$} & \multicolumn{2}{|c|}{$\begin{array}{c}\text { Primeira contagem } \\
(\%)\end{array}$} & \multicolumn{2}{|c|}{$\begin{array}{l}\text { Tempo médio de } \\
\text { germinação } \\
\text { (dias) }\end{array}$} & \multirow[t]{2}{*}{$\begin{array}{l}\text { Índice de velocidade de } \\
\text { germinação }\end{array}$} \\
\hline & Lote 1 & Lote 2 & Lote 1 & Lote 2 & Lote 1 & Lote 2 & \\
\hline 15 & $76 \mathrm{bB}$ & $95 \mathrm{aA}$ & $0 \mathrm{eA}$ & $0 \mathrm{bA}$ & $16 \mathrm{cB}$ & $10 \mathrm{cA}$ & $7,87 \mathrm{~d}$ \\
\hline 20 & $91 \mathrm{aB}$ & $98 \mathrm{aA}$ & $30 \mathrm{~dB}$ & $86 \mathrm{aA}$ & $8 \mathrm{bB}$ & $4 \mathrm{abA}$ & $18,56 \mathrm{c}$ \\
\hline 25 & $94 \mathrm{aA}$ & $99 \mathrm{aA}$ & $63 \mathrm{cB}$ & $88 \mathrm{aA}$ & $5 \mathrm{aA}$ & $5 \mathrm{bA}$ & $24,71 \mathrm{~b}$ \\
\hline 30 & $91 \mathrm{aA}$ & $96 \mathrm{aA}$ & $87 \mathrm{aA}$ & $96 \mathrm{aA}$ & $4 \mathrm{aB}$ & $3 \mathrm{aA}$ & $28,53 \mathrm{a}$ \\
\hline 35 & $88 \mathrm{aB}$ & $97 \mathrm{aA}$ & $80 \mathrm{abB}$ & $96 \mathrm{aA}$ & $4 \mathrm{aB}$ & $3 \mathrm{aA}$ & $26,55 \mathrm{ab}$ \\
\hline $20-30$ & $93 \mathrm{aA}$ & $99 \mathrm{aA}$ & $64 \mathrm{bcB}$ & $97 \mathrm{aA}$ & $5 \mathrm{aA}$ & $4 \mathrm{abA}$ & $25,10 \mathrm{~b}$ \\
\hline
\end{tabular}

Médias seguidas da mesma letra maiúscula na linha (lotes) e seguidas de mesma letra minúscula na coluna (temperaturas), não diferem 
germinação, levando de três a quatro dias para germinar. De modo geral, as temperaturas mais baixas, entre 15 e $20^{\circ} \mathrm{C}$, interferiram negativamente na velocidade de germinação para ambos os lotes, sendo necessários de oito a 16 dias para conclusão do teste.

Diante disso, foram identificadas as temperaturas de 30 e $35^{\circ} \mathrm{C}$ como as mais favoráveis ao processo germinativo na primeira contagem, tempo médio de germinação e índice de velocidade de germinação para ambos os lotes, tanto para lote de alto vigor (lote 2) como de baixo vigor (lote 1).

Após a identificação das temperaturas, foram elaboradas as curvas de germinação para o estabelecimento da data da primeira contagem e da contagem final do teste. Para as sementes de E. urophylla verificou-se que a avaliação da primeira contagem deve ser realizada no quarto dia após a semeadura e finalizado o teste de germinação no $10^{\circ}$ dia após a semeadura, quando foi constatada a estabilização da produção de plântulas normais após três contagens (Figura 1).

A data da primeira contagem foi identificada como sendo aos quatros dias, pois nessa data a germinação atingiu aproximadamente $50 \%$ daquela obtida ao final do teste, como recomendado por Tomaz et al. (2016) e Affonso et al. (2018). O tempo de 10 dias para a conclusão do teste de germinação de sementes de $E$. urophylla diverge do tempo de 14 dias recomendado para essa espécie pela Instrução Normativa para análise de sementes de espécies florestais (BRASIL, 2013).

\section{Discussão}

As variáveis germinação, primeira contagem e índice de velocidade de germinação no primeiro experimento não foram influenciadas pelos substratos, evidenciando que para a avaliação de lotes de sementes

FIGURA 1: Curva da germinação diária de sementes de dois lotes de Eucalyptus urophylla semeadas sobre papel a 30 e $35^{\circ} \mathrm{C}$.

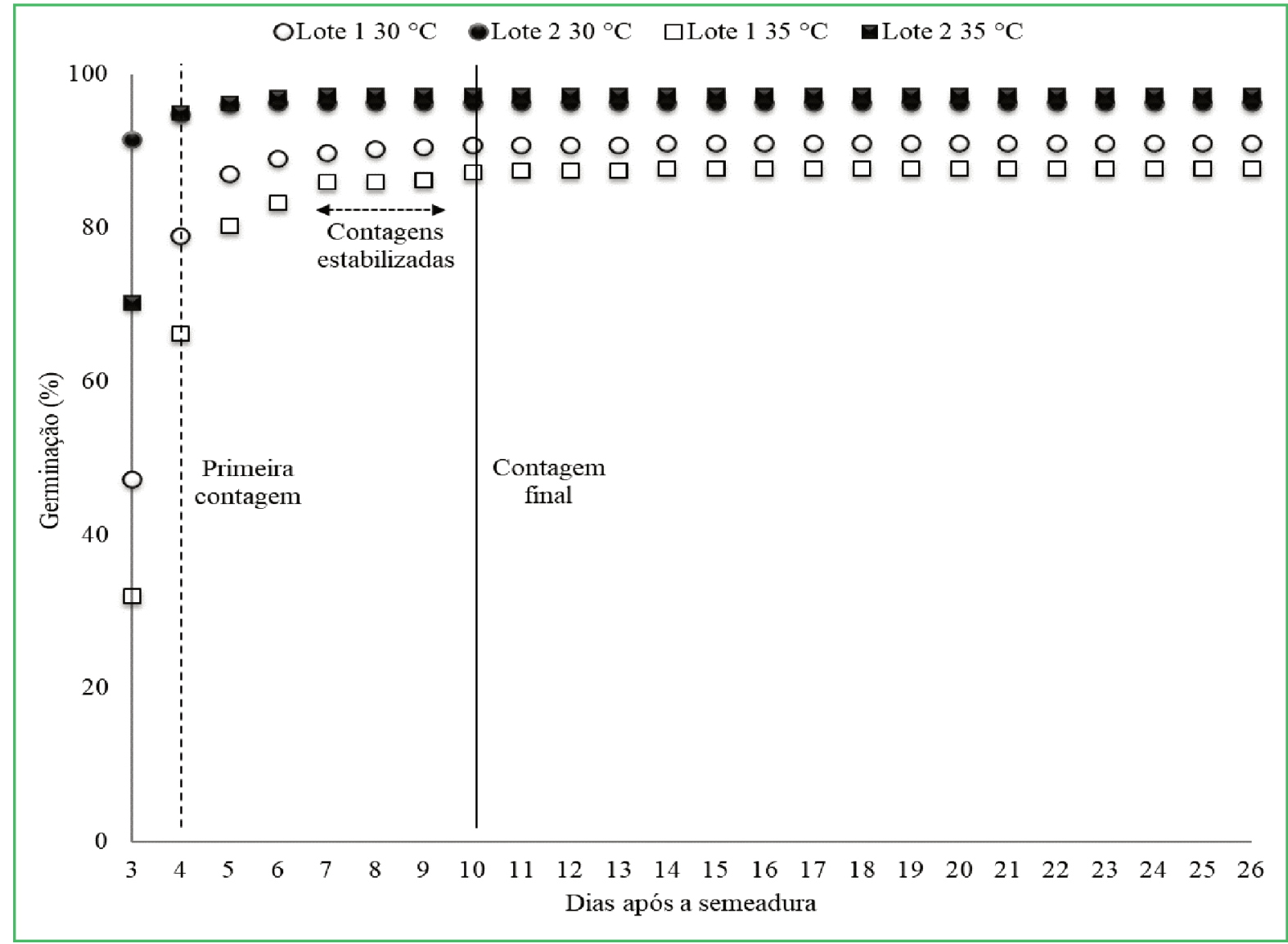


de E. urophylla a temperatura tem maior importância do que o substrato no qual será conduzido o teste. Portanto, o teste padrão de germinação de sementes dessa espécie pode ser conduzido tanto sobre papel quanto sobre areia.

Entretanto, quando objetivam-se a rapidez, praticidade e a redução de mão-de-obra, como ocorre nas análises laboratoriais, o substrato papel passa a ser indicado, pois o processo de montagem, condução e desmontagem do teste de germinação é mais rápido e prático, principalmente pela obtenção do material, esterilização, menor volume a ser manuseado, descarte do substrato utilizado e limpeza das caixas plásticas, como relatado por Barroso et al. (2010), Affonso et al. (2018) e Jeromini et al. (2019).

A germinação em ampla faixa de temperatura é um indicativo da alta capacidade adaptativa dessa espécie ao clima e ao estabelecimento em condições naturais, o que aumenta as suas chances de sobrevivência no campo (GUEDES et al., 2010, SILVA et al., 2017).

A diferença de velocidade de germinação em função da temperatura observada entre os lotes pode ser atribuída à qualidade superior do lote 2, pois sementes mais vigorosas apresentam menor necessidade de temperaturas próximas às ótimas para atingir a máxima germinação (CARVALHO; NAKAGAWA, 2012; LIMA et al., 2012), ou seja, lotes com sementes de maior vigor apresentam germinação uniforme e em menor tempo em condições adversas, como temperaturas sub e supraótimas durante esse processo, quando comparadas com sementes de lotes de menor vigor que, ao levarem mais tempo para germinar, ficaram expostas a tais condições. Tais resultados também foram observados na avaliação de lotes de sementes de milho (SBRUSSI; ZUCARELI, 2014).

Em testes de rotina nos laboratórios de análise de sementes, ao se padronizar o teste de germinação na faixa ótima de temperatura para a espécie, visa-se à máxima germinação em menor tempo, o que torna possível reproduzir e comparar os resultados (BRASIL, 2009; MARCOS FILHO, 2015).

Temperaturas inferiores à ótima tendem a reduzir a velocidade do processo de germinação, pois há redução da embebição da água pelas sementes, assim como redução na ativação enzimática para quebra de reservas, levando mais dias para estabilização, como verificado para Bidens pilosa L. (BARROS et al., 2017), Dalbergia cearensis Ducke (NOGUEIRAet al., 2014), Inga laurina (Sw.) Willd (BARROZO et al., 2014) e Senegalia tenuifolia (L.) Britton \& Rose (ARAÚJO et al., 2016).

O período de quatro dias para a primeira contagem de germinação é similar àquela recomendada para outras espécies do mesmo gênero Eucalyptus, ou seja, de três dias para E. camaldulensis Dehn, E. cinerea F. Mull. ex Benth e E. tereticornis Sm e cinco dias para E. grandis Hill ex Maiden e E. radiata Sieber ex DC (BRASIL, 2009; 2013), entretanto, apenas após o experimento foi possível identificar o período ideal.

Em contrapartida, o período para a contagem final pode ser reduzido em quatro dias, diminuindo, além do tempo para entrega do teste também os gastos com a manutenção do material em câmaras de germinação. Esse resultado ressalta a importância da realização de trabalhos de pesquisa para a elaboração das futuras Regras de Análise de Sementes de Espécies Florestais. Portanto, verificou-se que somente a bibliografia baseada em comunicação pessoal dos laboratoristas, como prescrito em Brasil (2013), não é suficiente para o estabelecimento da metodologia mais adequada.

O teste de germinação de sementes de E. urophylla deve ser realizado a 30 ou $35^{\circ} \mathrm{C}$ com semeadura sobre papel ou areia, e com contagem inicial e final aos quatro e 10 dias após a semeadura, respectivamente. Com base nesta pesquisa, mais testes podem ser realizados, para outros lotes e sementes de E. urophylla de outras procedências para garantir a confirmação dos resultados.

\section{Agradecimentos}

Ao Conselho Nacional de Desenvolvimento Científico e Tecnológico (CNPq) e à Coordenação de Aperfeiçoamento de Pessoal de Nível Superior (CAPES) pelo apoio à pesquisa. 


\section{Referências}

AFFONSO, C. E.; SILVA, G. Z. da; JEROMINI, T. S.; MARTINS, C. C. Germination test of Eucalyptus phaeotricha seeds. Revista Brasileira de Engenharia Agrícola e Ambiental, Campina Grande, v. 22, n. 9, p. 653-657, 2018.

ARAÚJO, A. M. S.; ASSIS, L. C. da S. L. G.; NOGUEIRA, N. W.; FREITAS, R. M. O. de; TORRES, S. B. Substrates and temperatures for the germination of seeds of Senegalia tenuifolia (L.) Britton \& Rose. Revista Caatinga, Mossoró, v. 29, p. 113-118, 2016.

BARROS, R. T.; MARTINS, C. C.; SILVA, G. Z. da; MARTINS, D. Origin and temperature on the germination of beggartick seeds. Revista Brasileira de Engenharia Agrícola e Ambiental, Campina Grande, v. 21, n. 7, p. 448-453, 2017.

BARROSO, C. M.; FRANKE, L. B.; BARROS, I. B. I. Substrato e luz na germinação das sementes de rainha-do-abismo. Horticultura Brasileira, Brasília, v. 28, n. 2, p. 236-240, 2010.

BARROZO, L. M. da; ALVES, E. U.; SILVA, R. dos S.; ANJOS NETO, A. P. dos; SANTOS NETA, M. dos M. S. dos; SILVA, B. F. da. Substratos e temperaturas para testes de germinação e vigor de sementes de Inga laurina (Sw.) Willd. Bioscience Journal, Uberlândia, v. 30, p. 252-261, 2014.

BRASIL. Regras para análise de sementes. Secretaria de Defesa Agropecuária. Brasília: MAPA/ACS, 2009. 395 p.

BRASIL. Instruções para análise de sementes de espécies florestais. Brasília: Secretaria Nacional de Defesa Agropecuária, Brasília: MAPA/ACS, 2013. 98 p.

CARVALHO, N. M.; NAKAGAWA, J. Sementes: ciência, tecnologia e produção. 5. ed. Jaboticabal: FUNEP, 2012. 590 p.

CETNARSKI FILHO, R.; CARVALHO, R. I. N. Massa da amostra, substrato e temperatura para teste de germinação de sementes de Eucalyptus dunnii Maiden. Ciência Florestal, Santa Maria, v. 19, n. 3, p. 257-265, 2009.

GUEDES, R. S.; ALVES, E. U.; GONÇALVES, E. P.; BRAGA JÚNIOR, J. M.; VIANA, J. S.; COLARES, P. N. Q. Substratos e temperaturas para testes de germinação e vigor de sementes de Amburana cearensis (Allemão) A. C. Smith. Revista Árvore, Viçosa, v. 34, p. 57-64, 2010.

IBGE - INSTITUTO BRASILEIRO DE GEOGRAFIA E ESTATÍSTICA. Produção da extração vegetal e da silvicultura. 2018. Disponível em: https://biblioteca.ibge.gov.br/visualizacao/ periodicos/74/pevs_2018_v33.

JEROMINI, T. S.; MUNIZ, R. A.; SILVA, G. Z.; MARTINS, C. C. The envelope method and substrate wetting in the germination test of onion seeds. Revista Ciência Agronômica, Fortaleza, v. 50, n. 1, p. 169-176, 2019.

LABOURIAU, L. G. Seed germination. Washington: Secretaria Geral da Organização dos Estados Americanos, 1983. 174 p.

LIMA, C. R.; PACHECO, M. V.; BRUNO, R. D. L. A.; FERRARI, C. S.; JÚNIOR, J. M. B.; BEZERRA, A. K. D. Temperaturas e substratos na germinação de sementes de Caesalpinia pyramidalis TUL. Journal of Seed Science, Londrina, v. 33, n. 2, p. 216-222, 2012.
LOPES, E. D.; AMARAL, C. L. F.; NOVAES, A. B. Desempenho no campo de mudas de Eucalyptus urophylla, Eucalyptus camaldulensis e Corymbia citriodora produzidas em diferentes recipientes. Floresta, Curitiba, v. 44, n. 4, p. 589-596, 2014.

MAGUIRE, J. D. Speed of germination-aid in selection and evaluation for seedlings emergence and vigor. Crop Science, Madison, v. 2, n. 1, p. 176-177, 1962.

MARCOS FILHO, J. Fisiologia de sementes de plantas cultivadas. Vol. 1, 2. ed. Londrina: ABRATES, 2015. 659 p.

MARTINS, C. C.; MARTINELLI, A.; NAKAGAWA, J. Estágio de colheita e substrato para o teste de germinação de sementes de ipê (Tabebuia chrysotricha (Mart. ex DC.) Standl). Revista Árvore, Viçosa, v. 32, p. 27-32, 2008.

MARTINS, C. C.; PEREIRA, M. R. R.; LOPES, M. T. G. Germinação de sementes de eucalipto sob estresse hídrico e salino. Bioscience Journal, Uberlândia, v. 3, p. 318-329, 2014.

NOGUEIRA, F. C. B.; GALLÃO, M. I.; BEZERRA, A. M. E.; MEDEIROS FILHO, S. Efeito da temperatura e luz na germinação de sementes de Dalbergia cearensis Ducke. Ciência Florestal, Santa Maria, v. 24, n. 1, p. 995-1005, 2014.

SANTANA, D. G. de.; ANASTÁCIO, M. R.; LIMA, J. A. de.; LIMA, M. B. de. Germinação de sementes e plântulas de pau-santo: uma análise crítica do uso de correlação. Revista Brasileira de Sementes, Londrina, v. 32, n. 3, p. 134-140, 2010.

SANTOS, L. N.; FERNANDES, H. C.; SILVA, R. M. F.; SILVA, M. L.; SOUZA, A. P. Evaluation of costs of harvester in cut and processing of eucalyptus wood. Revista Árvore, Viçosa, v. 41, n. 5, p. 1-9, 2017.

SBRUSSI, C. A. G.; ZUCARELI, C. Germinação de sementes de milho com diferentes níveis de vigor em resposta à diferentes temperaturas. Semina: Ciências Agrárias, Londrina, v. 35, n. 1, p. 215-226, 2014.

SILVA, R. B.; MATOS, V. P.; FARIAS, S. G. G. de; SENA, L. H. de M.; SILVA, D. Y. B. de O. Germinação e vigor de plântulas de Parkia platycephala Benth. em diferentes substratos e temperaturas. Revista Ciência Agronômica, Fortaleza, v. 48, p. 142-150, 2017.

SOUZA, C. S.; FREITAS, M. L. M.; MORAES, M. L. T.; SEBBENN, A. M. Estimativas de parâmetros genéticos para caracteres quantitativos em progênies de polinização aberta de Eucalyptus urophylla. Floresta, Curitiba, v. 41, n. 4, p. 847-856, 2011.

TOMAZ, C. A.; MARTINS, C. C.; SANCHES, M. F. G.; VIEIRA, R. D. Time reduction for surinam grass seed germination test. Ciência e Agrotecnologia, Lavras, v. 39, n. 5, p. 488-497, 2015.

TOMAZ, C. A.; MARTINS, C. C.; SILVA, G. Z. da; VIEIRA, R. D. Period of time taken by Brachiaria humidicola (Rendle) Scheweick seed to complete germination. Semina: Ciências Agrárias, Londrina, v. 37, p. 693-700, 2016.

WILCKEN, C. F.; LIMA, A. C. V.; DIAS, T. K. R.; MASSON, M. V.; FERREIRA FILHO, P. J.; POGETTO, M. H. F. A. Guia prático de manejo de plantações de eucalipto. Botucatu: FEPAF, 2008. $25 \mathrm{p}$. 